\title{
Los movimientos obreros de España y Argentina, desde sus orígenes hasta mediados del siglo XX: Propuestas para un diálogo historiográfico
}

\author{
Esteban Piliponsky
}

\begin{abstract}
Resumen: El presente escrito es un trabajo historiográfico en donde nos proponemos relacionar sucintamente las historias del movimiento obrero argentino y español, desde el nacimiento de los mismos hasta mediados del siglo XX. Consideramos que dichas historias han sido poco cotejadas entre los investigadores de la temática. Nuestro objetivo es delinear algunas de las causas de esta situación, a la vez que enunciar propuestas para comenzar a revertirla justificando la utilidad de ello. Para esto realizaremos un esbozo comparativo en tres aspectos: los recorridos similares por los que atravesaron sus historiografías respecto a los problemas de la clase obrera organizada; los procesos históricos similares y debates ideológicos y políticos que caracterizaron a uno y otro movimiento; y las características que han tenido en cada caso los procesos que definimos como estatización del movimiento obrero, sucedidos en Argentina bajo el régimen peronista y en España con el franquismo. Finalmente expondremos una bibliografía, dividida por país y por grande ejes temáticos, con los principales aportes de los últimos 20 años.
\end{abstract}

Palabras clave: Movimiento Obrero; Historiografía; España-Argentina.

\begin{abstract}
The present essay it's a historiography work where we propose to make a brief relationship between the stories of the Argentinean labor movement and the Spain one, since the origins of each one until middle of S. XX. We consider that those stories have been not enough compared between investigators of these topics. Our objective is to delineate some causes of the situation, also announce propositions to revert this justifying it's utility. For these we will make an outline comparative in three aspects: the similar trajectory that there historiography follow in relation to the organized work class problems; the similar historic process and ideological and politic debates that characterized both movements; and the characteristics that each one have in order of what we defined as government control of labor movement in Argentina under peronism regime and in Spain with the franquism. Finally we will expose bibliography separated by country and by big topics, with the principal contributions of the last 20 years.
\end{abstract}

Key words: Workers Movement; Historiography; Spain-Argentina.

\section{INTRODUCCIÓN}

El cotejo y las comparaciones entre diferentes zonas geográficas y/o etapas históricas, es de una riqueza innegable para las ciencias sociales. En el caso de la historiografía, lo más interesante de esta clase de estudios no se encuentra en hallar las coincidencias o remarcar las similitudes, sino en descubrir las diferencias y los contrastes de situaciones análogas. Pero, al mismo tiempo, es necesario encontrar características similares

* Professor da Universidad Naioncal de Tucumán (CONICET-UNT). 
entre las realidades a cotejar, que justifiquen el estudio. En el presente escrito nos proponemos demostrar la utilidad de relacionar las historias del movimiento obrero argentino y español, desde el nacimiento de los mismos hasta mediados del siglo XX. Por ello esbozaremos, como primer acercamiento a dicho objetivo, tanto aspectos comunes como contrastantes entre ambos casos.

La idea que perseguimos no es simplemente alentar a los historiadores de temáticas obreras a realizar trabajos que se centren en el cotejo de ambas realidades, sino también invitar a los mismos a indagar, en el marco de los estudios específicos de sus países, en las investigaciones y los procesos históricos acaecidos en el otro territorio en cuestión. Este ejercicio ha sido muy poco practicado en las investigaciones sobre los tópicos que analizaremos, a pesar de los lazos económicos, políticos, sociales y culturales entre ambas regiones. Se buscará entonces exponer la potencialidad de revertir dicha carencia, a la vez que esbozar algunas ideas preliminares sobre las causas de la misma.

Existen diversos motivos que nos llevan a considerar pertinente e incluso necesario, el diálogo entre las historias del movimiento obrero en los dos países durante el espacio temporal propuesto. En primer lugar, existen procesos aseméjales en estos Estados en el aspecto económico. Sin olvidar que uno y otro se encuentran en ubicaciones geopolíticas muy disímiles, ambos tuvieron un desarrollo industrial limitado al mismo tiempo que mucho de su peso productivo en zonas rurales. En consonancia con ello, las experiencias ideológicas y políticas de sus movimientos obreros recorrieron caminos evidentemente cotejables.

Pero estas similitudes no responden tan sólo a las realidades semejantes en la estructura macroeconómica. Se debe tener en cuenta también la realidad interna de dichos países, particularmente respecto a la heterogeneidad regional de cada uno. La misma no es completamente igualable en cada caso. España está dividida entre las zonas de mayor industrialización, como Catalunya y el país Vasco, y los territorios más abocados a las actividades primarias. Esto generó disputas en torno a las autonomías regionales, provocando tensiones entre el centro político, radicado en Madrid, y los espacios de mayor capacidad productivo-económicas. En Argentina, en cambio, el poder político y el económico están centralizados excesivamente en la zona metropolitana, en torno a Buenos Aires, mientras las provincias del interior del país pujan por una participación más activa en ambos aspectos. Lo que si es común en ambos países son las tensiones entre centro y periferia que también tuvieron y tienen consecuencias tanto en las organizaciones obreras como en la producción historiográfica.

Por otro lado, es importante el flujo e intercambio de ideas y de dirigentes obreros que debieron vivir en ambos lados del océano producto de la represión y las crisis económicas. Sin duda esto último sucedía en el conjunto de los movimientos obreros del mundo occidental, pero es particularmente fluida la relación que se entabló entre España y Argentina en contraste con las escasas investigaciones que tienen en cuenta tal situación. Sumado a ello, otro factor destacable es el número de migrantes europeos durante el período en cuestión, muchos de ellos españoles, hacia la Argentina, tema que sí ha cobrado 
cierta fuerza como objeto de estudio de las ciencias sociales a partir del interés sobre los movimientos transnacionales en el mundo de los trabajadores.

Desarrollaremos un esbozo comparativo respecto a España y Argentina en tres aspectos que consideramos importantes, aunque en absoluto representan la totalidad de las cuestiones contrastables. En primer lugar buscaremos apuntar los recorridos similares por los que atravesaron las historiografías de ambos países respecto a los problemas de la clase obrera organizada. Luego resaltaremos procesos históricos similares y debates ideológicos y políticos que caracterizaron a uno y otro movimiento, en donde aparece un campo fértil para cotejar experiencias entre los territorios. $Y$, en tercer lugar, nos centraremos en las características que han tenido en cada uno de estos países los procesos que definimos como estatización del movimiento obrero, sucedidos en Argentina bajo el régimen peronista y en España con el franquismo. El ascenso de dichos gobiernos marcó la finalización del período que nos proponemos indagar, siendo claramente un momento de ruptura en la historia de cada uno de estos Estados. A ello se debe la importancia de esta época dentro de los estudios históricos, y la necesidad de tratarlos aquí en el marco de nuestra propuesta de comparar los procesos sociales de las mencionadas regiones.

Finalmente expondremos una bibliografía, dividida por país y por grandes ejes temáticos. La misma será en definitiva, el mayor aporte del presente trabajo en tanto referencia para aquellos investigadores que adscriban a la propuesta que se hace desde este escrito. No se pretende con esta abarcar la totalidad de la producción sobre el tema, sino enumerar las principales obras y autores que trabajan la temática en ambos países, particularmente en los últimos 25 años.

\section{LA HISTORIOGRAFÍA DEL MOVIMIENTO OBRERO EN ESPAÑA Y ARGENTINA}

Si observamos el devenir de la historiografía acerca del movimiento obrero en España y Argentina, se puede denotar una correspondencia en cuanto a las etapas en que estas se fueron produciendo, como así también en muchos de los tópicos principales que marcan los debates en cada uno de los casos. Respecto al primer punto, ambas historias han sido emprendidas primeramente por los propios protagonistas de la clase obrera organizada, respondiendo a la necesidad de reconstruir el devenir de sus organizaciones y/o partidos. Pero luego, la "academia" de historiadores ha denostado dicha producción que en Argentina fue catalogada con el mote de historia militante, considerando la misma de menor valor. Frente a ello, Pere Gabriel por ejemplo, remarca que hay continuidad en el caso español entre este tipo de producción escrita por los propios protagonistas de las organizaciones obreras, o los intelectuales vinculados a las mismas, y la posterior realizada en el ámbito académico de las universidades. ${ }^{1}$ La misma afirmación podría hacerse extensiva al caso argentino. A pesar de la necesidad de los historiadores profesionales de diferenciarse de los escritos excesivamente apologéticos del movimiento obrero que precedieron sus propios

\footnotetext{
${ }^{1}$ GABRIEL SIRVENT, Pere. “A vueltas y revueltas con la historia social obrera en España. Historia obrera, historia popular e historia contemporánea", Historia social, № 22, Valencia, 1995, pp. 43-53.
} 
estudios, en la actualidad se reclama su uso como parte del estado del arte. Dicha revaloración es reivindicada por el propio Gabriel, o en el caso del país latinoamericano por las afirmaciones en la misma dirección de Nicolás Iñigo Carrera, ${ }^{2}$ entre otros.

A fines de los años '60 y comienzos de los '70, se produjo en ambos países un importante crecimiento cualitativo y cuantitativo de los estudios sobre el movimiento obrero, en donde la temática fue abordada, además, por investigadores profesionales de la historia o de otras ciencias sociales. Esto se realizó en un contexto de convulsión social a nivel mundial. Pero fue también consecuencia de la situación interna de estos dos Estados, la cual incluía un importante crecimiento de la movilización y la fuerza de los trabajadores organizados en ambos territorios. Tal escenario incitó a numerosos científicos sociales, en la mayoría de los casos identificados ideológicamente con las diferentes aspiraciones de los obreros, a preguntarse sobre el pasado y el desarrollo de la clase obrera, con el fin de comprender mejor las causas y las potencialidades del momento histórico que estaban viviendo.

Al mismo tiempo, imperaba en estos dos países un alto grado de censura ejercido por sus respectivos gobiernos, que se mantenía desde las décadas precedentes. Ello explica en parte, la excesiva mirada comparativa hacia los países más desarrollados de Europa occidental, principalmente Inglaterra y Francia, y el uso de sus paradigmas epistemológicos, frente a la ausencia de trabajos propios debido a la dificultad de su producción. Incluso, muchas de las mencionadas investigaciones se produjeron en el extranjero. Tal es el caso en Argentina, por ejemplo, de los trabajos de Edgardo Bilsky, exiliado en Francia, o de Ricardo Falcón quien realizó sus primeros escritos basado en los archivos del reconocido Instituto Internacional de Historia Social de Ámsterdam. ${ }^{3}$ Naturalmente la reiterada referencia sobre los Estados más avanzados económicamente, y por ende más adelantados también en el ámbito de la producción científica, no es algo excluyente de la temática obrera. Pero en este caso se vio potenciada por las condiciones políticas en las que este tópico comenzó a ser de interés entre los científicos sociales argentinos y españoles.

Sin negar la importancia de las comparaciones con los países centrales, no cabe duda que el desarrollo del capitalismo en esos territorios dista de lo sucedido en los dos casos que estamos tratando. De allí la riqueza de cotejar ambas experiencias, mucho más semejantes entre si que las sucedidas en otras latitudes. Llamativamente, sin embargo, las comparaciones de Argentina con España y viceversa, son escasas inclusive hoy donde la circulación de las investigaciones es mucho más fluida y de mayor acceso que hace 40 años. Si bien existen trabajos de este tipo, donde se cotejan los casos de Argentina y Brasil o

\footnotetext{
2 IÑIGO CARRERA, Nicolás. "La clase obrera argentina a comienzos de los '30. Sistema institucional, partidos y clase: apuntes para una lectura crítica", jornadas: a 40 años del Cordobazo: ciento treinta años de historia de luchas de la clase obrera en Argentina, 1878-2008, 2009. En línea:

http://historiapolitica.com/datos/biblioteca/icarrera1.pdf

${ }^{3}$ BILSKY, Edgardo J. La FORA y el movimiento obrero (1900-1910), vols. 1 y 2, Buenos Aires: CEAL, 1985. La mayoría de las obras de Bilsky se produjeron en Francia, esta es una de las más importantes. Falcón, Ricardo. Los orígenes del movimiento obrero (1857-1899), Buenos Aires: CEAL, 1984.
} 
España e Italia por ejemplo, el diálogo entre las realidades de los países que nos ocupan aquí es prácticamente nula en cuanto a la historia movimiento obrero.

Por último existe otro parangón en las características de la historiografía de ambos Estados: la producción sobre el movimiento obrero sufrió un importante decrecimiento durante los años '90. Al igual que en el apogeo de trabajos sobre la temática, 40 años antes, son múltiples las causas que explican esta depreciación. Entre las principales se debe destacar la debilidad en la que cayeron las organizaciones de los trabajadores en contraposición con el auge de la ideología neoliberal, que terminó de consolidar su hegemonía en Argentina y España durante la década mencionada. Particularmente en el ámbito académico, y en un importante porcentaje como consecuencia de lo recién explicado, el clima de época dominante bajo el reinado de la llamada "economía de mercado", conllevaba la idea de la desaparición de la clase obrera como actor protagónico de la historia contemporánea. Esto se vio potenciado en las ciencias sociales con la corriente denominada "giro lingüístico" que, aunque no tuvo estudios históricos particulares que adscribiesen a esa línea de pensamiento, afectó la producción en este campo del saber. ${ }^{4}$ En consecuencia la gran mayoría de los investigadores remplazaron como objeto de estudio a los trabajadores y a sus organizaciones, para ubicar en el centro de la escena otro tipo de sujetos y de identificaciones sociales, como los que giran en torno al ciudadano, las diferencias de género o generacionales, las afinidades creadas en torno a la situación de los inmigrantes o exiliados, etc. Es innegable la utilidad de dichos tópicos, algunos de larga data y revitalizados en los últimos años, y otros prácticamente novedosos. El problema radica en que gran parte de los trabajos sobre el movimiento obrero se han preocupado por soslayar, ignorar o, en algunos casos, negar, la ubicación de los sujetos dentro del sistema productivo, es decir, la identidad de clase.

Debemos hacer la salvedad, sin embargo, de que esta situación vivió una importante ruptura en la Argentina tras la crisis económica y política estallada en 2001, la cual provocó una explosión exponencial de las temáticas obreras. ${ }^{5}$ En España en cambio, si bien hubo un ritmo de escritos mayor al de aquel país en los ' 90 , la temática conservó cierta flaqueza durante los últimos 20 años en forma constante, más allá de prometedores proyectos de investigación que comenzaron a resurgir en el último tiempo y que permiten suponer un cambio en la tendencia decreciente que estamos exponiendo.

De todos modos, la última etapa de la historiografía sobre el movimiento obrero también llevó a un crecimiento cualitativo en los enfoques sobre el tema. Como remarca Gabriel hubo un acercamiento en los '90 a la idea de cultura política en las investigaciones

\footnotetext{
4 Ver al respecto: BARRIO ALONSO, Ángeles. "Clase obrera y movimiento obrero: ¿dos compañeros inseparables?”, Cuadernos de historia contemporánea, № 30, 2008, pp. 83-104. En línea:

http://dialnet.unirioja.es/servlet/articulo?codigo $=2816530$

${ }^{5}$ Es cierto que existió en Argentina un importante crecimiento en la totalidad de la producción en las ciencias sociales durante la primera década del siglo XXI respecto a la última de la centuria anterior, y no existen aun trabajos que nos permitan evaluar porcentualmente con exactitud el incremento dentro de estos de la temática que estamos analizando. De todos modos, la legitimidad que han cobrado en el ámbito académico los estudios sobre clase y movimiento obrero entre un momento y el otro, es de una profundidad indudable.
} 
sobre los trabajadores aunque, como contrapone el mismo autor, aun este pendiente una historia social del movimiento obrero. Resulta alentador comprobar que esta falencia se encuentra en la agenda de prioridades de los investigadores, principalmente en el debate acerca de la compleja relación entre movimiento obrero y el conjunto de la clase, ${ }^{6}$ con interrogantes que abarcan desde el grado de representación de los primeros respecto a los segundos, hasta el lugar que ocupa cada uno de estos actores en las estrategias políticas que llevan adelante los trabajadores como tales, en cada momento histórico.

En síntesis, y tras haber esbozado sucintamente las principales etapas de la historiografía obrera española y argentina cuyas experiencias son muy cercanas como buscamos demostrar, la temática del mundo obrero se encuentra hoy en ambos países en una tendencia alentadora que presupone un cambio de signo respecto a lo ocurrido principalmente en la última década del siglo XX. En ese marco es que vemos interesante la propuesta de entablar un diálogo entre los trabajos españoles y argentinos. No nos referimos con ello tan sólo a investigaciones específicas de historia comparada, sino también la inclusión en los trabajos específicos en cada país de los principales avances que se producen en el otro, ya sea en las citas bibliográficas como en hechos o procesos puntuales que el historiador considere interesante cotejar. Como hemos mencionado es un ejercicio que se ve comúnmente respecto a los países más desarrollados o a los vecinos regionales de cada uno de estos Estados, pero es prácticamente inédito entre los dos territorios que estamos analizando.

\section{PROCESOS SOCIALES Y DEBATES OBREROS EN COMÚN}

El interés de poner a dialogar a las historiografías argentina y española respecto al movimiento obrero no se reduce a las coincidencias en las etapas de desarrollo entre ambas. A ello debe añadirse otras similitudes, quizás más importantes e útiles para las investigaciones sobre la temática. Existen numerosas correspondencias en los debates que se realizan en un país y otro en torno a los trabajadores y sus organizaciones. Sin duda esto responde a un paradigma científico-social común, heredado en general de las universidades francesas e inglesas. Pero también, y no en menor grado, a las coincidencias en los procesos económicos, políticos y culturales de ambas regiones.

Respecto al surgimiento de la clase obrera como actor social y político, en los dos casos en cuestión el mismo se da a fines del siglo XIX, en un contexto internacional signado por la segunda revolución industrial y el ascenso del imperialismo principalmente en los países centrales. Por su parte, tanto Argentina como España mantenían el mayor peso económico y poblacional en las zonas rurales, mientras se activaba un proceso de industrialización mayormente liviano y de crecimiento de sus principales ciudades sostenido por la economía de servicios y la producción para el consumo interno. Además tenían en común una profunda heterogeneidad regional que provocaba diferencias marcadas al

\footnotetext{
${ }^{6}$ Un ejemplo de esto para el caso argentino: AAVV. Nuevo Topo. Revista de historia y pensamiento crítico. Dossier: La Burocracia Sindical, № 7, Buenos Aires, 2010.
} 
interior de cada uno de estos Estados. La realidad económica común, sumada al clima ideológico del movimiento obrero a nivel mundial a partir de sus organizaciones (la I pero particularmente la II internacional, vigente desde 1890), ayudan a entender las coincidencias en las corrientes políticas entre los dos países analizados. A ello debe sumarse el permanente flujo de inmigrantes europeos, entre los cuales había un importante porcentaje de españoles, que desembarcaron en tierras argentinas.

Un punto de coincidencia entre dichos países, y de los más destacados sin duda, es el poderoso movimiento anarquista desarrollado como una de las primeras corrientes políticas dentro de una y otra clase obrera. Hacia principios del siglo XX ambas sociedades contaban con dos de los movimientos ácratas más importantes a nivel mundial, los cuales además mantenían un intercambio constante de escritos e incluso de militantes. A pesar de esto, son escasas en la actualidad las referencias o al menos las citas bibliográficas en los estudios de cada país, respecto al otro. Quizás un caso ejemplificador sea el reciente libro de Dolors Marín, un muy completo repaso de la historia de los anarquistas en la península ibérica en donde la referencia al caso argentino es nula, tanto en el cuerpo del mismo como en la enumeración de obras literarias catalogadas. ${ }^{7}$

Si esta carencia es llamativa para los primeros años del siglo XX, la situación es lógicamente similar para los años siguientes en donde la mencionada ideología vive un retroceso dentro del movimiento obrero argentino. Sin embargo, estudios recientes demuestran que la misma no desapareció en absoluto en aquel país sino por el contrario, mantuvo su presencia entre los trabajadores organizados. ${ }^{8}$ Por lo tanto, en el marco de nuestra propuesta de entablar un diálogo en los estudios históricos de uno y otro Estado, el caso del anarquismo es uno de los más importantes pero no sólo durante el surgimiento de las primeras organizaciones obreras, sino también en los años posteriores hasta mediados de siglo.

Por otro lado, contemporáneo al nacimiento de las organizaciones gremiales, aparecen algunas cuestiones en debate que perduraron durante las décadas siguientes, y en algunos casos hasta nuestros días. Las mismas son retomadas por los historiados y repensadas desde las problemáticas de su propio presente. Enunciaremos aquí algunas de ellas, nuevamente comunes a estos países pero con muy poco diálogo entre los estudios de un espacio y el otro. Una de las querellas más interesantes es en torno al grado de centralización o federalismo de los gremios de segundo y tercer grado. Otra se dio entre los sindicatos de trabajadores creados o vinculados a los primeros partidos socialistas, fundados a fines del siglo XIX. Frente a ello comienzan las discusiones al seno de dichos partidos y de

\footnotetext{
7 MARín, Dolors. Anarquistas: un siglo de movimiento libertario en España, Barcelona: Ariel, 2010. Las principales obras de los últimos años sobre el anarquismo argentino y español están enumeradas en la bibliografía.

${ }^{8}$ Un ejemplo de estas investigaciones es la de LÓPEZ TRUJILLO, Fernando. Vidas en rojo y negro. Una historia del anarquismo en la "Década Infame", La Plata: Letra Libre, 2005. Una reflexión historiográfica sobre el tema en NIETO, Agustín. "Notas críticas en torno al sentido común historiográfico sobre 'el anarquismo argentino"”, A contra corriente, una revista de historia social y literatura de América Latina, Vol. 7, № 3, 2010, pp. 219-248. En línea: http://www.ncsu.edu/acontracorriente/spring_10/articles/Nieto.pdf
} 
las organizaciones obreras, sobre la relación que debía existir entre una y otra entidad. También surge una profunda lucha con el pensamiento anarquista y sindicalista revolucionario (corriente enarbolada a partir de las ideas del teórico George Sorel) a cerca de los beneficios o perjuicios que conllevaba para los intereses obreros el vínculo con partidos políticos que buscasen representar a los asalariados. ${ }^{9}$ Una vez más debemos mencionar que estas temáticas no son exclusivas del caso argentino y español, pero en estos países se suceden contemporáneamente, con realidades económicas y sociales comunes, y con dos movimientos obreros en continuo vínculo. Además, las coincidencias con la realidad de otros países no impugna la utilidad de ligar el devenir histórico de dos geografías con históricos vínculos en su cultura política.

Otro punto de común interés en ambas historiografías, son las pesquisas a cerca de las políticas sociales encaradas por los gobiernos de turno, pero también por la Iglesia Católica a partir de su Doctrina Social, y por los Partidos Socialistas o grupos liberales progresistas. Si bien las políticas sociales, surgidas en España a fines del siglo XIX y en Argentina sobre comienzos del XX, responden a una realidad de alarmante precariedad entre las capas bajas de la población, existe el debate en torno a cuál fue finalmente la causa que desencadenó la "decisión política" de actuar al respecto. Es interesante en este sentido el debate entablado por los historiadores argentinos Eduardo Zimmermann y Juan Suriano. El primero considera que el aspecto fundante de la política social en el país debe rastrearse en el trabajo de los intelectuales reformistas de principio del siglo XX. El segundo, en tanto, refutó esta idea argumentando que para comprender el surgimiento de la legislación laboral hay que centrarse principalmente en la situación económico-social y en la presión de algunos sectores obreros, quienes reclamaban contra ésta. ${ }^{10}$ Asimismo, numerosos referentes de la Iglesia coincidirían con la postura de Zimermann pero atribuyendo la iniciativa de las políticas sociales a sus referentes de entonces, es decir a los políticos y/o intelectuales pero militantes del catolicismo, algunos de los cuales alcanzaron cargos legislativos en la argentina del orden conservador.

Respecto al movimiento obrero, lo interesante es ver la función del Estado y de otras organizaciones de la sociedad civil, principalmente la Iglesia, en el surgimiento de los gremios de trabajadores. Existe aun la postura, aunque minoritaria en el ámbito académico, de que los sindicatos surgen por y para la defensa de los derechos otorgados por el Estado liberal conservador, antes que como instituciones que reclamaron y lograron con su accionar dicha legislación. Este debate puede extenderse a lo largo del tiempo en torno a la relación

\footnotetext{
${ }^{9}$ Para el caso español ver: PÉREZ LEDESMA, Manuel. "Partido y sindicato. Unas relaciones no siempre fáciles", en JULIÁ DÍAZ, Santos (coord.), El socialismo en España: desde la fundación del PSOE hasta 1975, Madrid: Editorial Pablo Iglesias, 1986, pp. 213-229. Para el argentino: CAMARERO, Hernán. "Socialismo y movimiento sindical: una articulación débil. La COA y sus relaciones con el PS durante la década de 1920", en CAMARERO, Hernán y HERRERA, Carlos M. (eds.). El Partido Socialista en Argentina. Sociedad, política e ideas a través de un siglo, Buenos Aires: Prometeo Libros, 2005.

${ }^{10}$ ZIMMERMANN, Eduardo. "Los intelectuales, las ciencias sociales y el reformismo liberal: Argentina 18901916", Desarrollo económico, no 124. v31, 1992, pp. 545-564. SURIANO, Juan. "Una aproximación a la definición de la cuestión social en Argentina", en SURIANO, Juan (comp.), La cuestión social en Argentina 18701943, Buenos Aires: La Colmena, 2000.
} 
de causa-consecuencia que tuvieron el movimiento obrero y las políticas sociales desde el comienzo de aquel y hasta el crecimiento de las funciones del Estado durante la etapa de entreguerras y la II guerra mundial.

Dentro del mismo período recién mencionado, podemos encontrar una característica política común a los asalariados organizados de España y Argentina. Hasta el final de la guerra civil en aquel país, y el surgimiento del peronismo en este, una de las cualidades más importantes de los sindicatos en ambos espacios fue la heterogeneidad de corrientes políticas actuantes en su seno. En torno a las grandes líneas de pensamiento: anarquistas, socialistas, sindicalistas revolucionarios (sorelianos) y comunistas, surgió un variopinto de experiencias ideológicas y organizativas que convivieron dentro del mundo obrero de ambos lugares. Prueba de ello es la numerosa bibliografía dedicada a cada una de estas ideologías políticas del movimiento obrero en ambos países, parte de la cual detallamos al final del presente trabajo bajo la clasificación de "corrientes políticas", centrándonos solo en los más recientes.

Más allá de la clásica disputa entre reformismo y revolución, las diferentes corrientes debatían sobre puntos como: la relación con el Estado, los gobiernos y los partidos; la dicotomía entre centralismo y confederación (muy importante en dichos países por sus marcadas diferencias regionales), la función de la huelga como arma de los trabajadores, la forma de organización en el lugar de trabajo; entre muchos otros. Naturalmente la convivencia entre estas líneas fue en numerosas ocasiones de disputa, cuando no directamente belicosas. Se jugaba en ella la hegemonía dentro de conjunto de los obreros organizados, y por ende la dirección política mayoritaria que este debía seguir. Pero hasta los sucesos de mediados de siglo, mencionados anteriormente, ninguna fuerza había logrado desarraigar por completo a la otra, lo que dio como resultado un movimiento obrero heterogéneo ideológica y políticamente que se mantuvo con esa característica durante más de medio siglo.

\section{LA ESTATIZACIÓN DEL MOVIMIENTO OBRERO: DOS CASOS COTEJABLES}

Los regímenes franquista y peronista generaron dentro del mundo obrero organizado de sus países una transformación que, si bien se produjo mediante procesos muy diferentes, consideramos que pueden ser comparadas en tanto produjeron un resultado similar: la estatización del sindicalismo asalariado. Esta transformación ha sido largamente estudiada en ambos países, pues es considerada un punto de inflexión en la historia política de los dos Estados durante el siglo XX. Sin embargo, las reticencias de los historiadores a realizar comparaciones entre los dos procesos es más pronunciada que otros tópicos y es, quizás, una de las múltiples causas para explicar la poca comunicación que existe entre los relatos más generales sobre los movimientos obreros de España y Argentina.

Esbozaremos una explicación tentativa de este alejamiento: como todo proceso de dominación, conviven en el mismo una cuota de consenso y otra de coerción. La dictadura de Franco se erigió en España tras una feroz guerra civil que dividió la sociedad en dos 
bandos fuertemente enfrentados. Las organizaciones obreras existentes hasta el estallido de dicho conflicto, junto a sus principales dirigentes, quedaron claramente identificados con el bando perdedor y se encontraron derrotadas tras la contienda. Esto llevó a centrar los estudios históricos en torno al uso de la fuerza por parte del Estado fascista en detrimento de las libertades sindicales, y a las resistencias aisladas que los trabajadores pudieron realizar en un contexto de extremo autoritarismo y represión. ${ }^{11}$

Por el contrario, el ascenso de Perón al poder fue acompañado por una alianza con un importante sector de la dirigencia y las bases obreras que apoyaron al entonces Coronel del ejército argentino. La historiografía en este país fue cambiante respecto a las posturas sobre los orígenes del régimen, en consonancia con las diversas transformaciones gubernamentales que se vivieron en aquel pues, a diferencia del franquismo que se mantuvo a la cabeza del Estado hasta la muerte de su líder, el peronismo fue desplazado del poder ejecutivo en 1955. De todos modos la posición dominante entre los estudios sociales, al menos en los últimos 30 años, resalta el consenso logrado por dicho movimiento político hacia los asalariados organizados antes de su aparición. En estos estudios, el objetivo perseguido es explicar por qué los trabajadores optan por la opción populista como estrategia política caracterizando tal fenómeno en la realidad argentina, como el ya mencionado pacto entre una fracción de la clase y el movimiento obrero con otra de las clases dirigentes, representada por fuerzas militares. Entre las muchas consecuencias que tuvo este proceso, es destacable para el tema que analizamos aquí fue el del desplazamiento casi completo de las corrientes de izquierda que habían tenido fuerte presencia política y cultural entre los asalariados hasta el surgimiento del mismo.

Sin embargo existen líneas de investigación, aunque generalmente minoritarias aun o en el mejor de los casos incipientes, en donde se pretende reflejar la "otra cara de la moneda" sobre ambos regímenes, vale decir, los elementos de consenso y cooptación del franquismo sobre las masas, en las que claramente el componente obrero es una parte importante; y por otro lado los usos de la coerción y de la represión por parte del peronismo contra las minorías que iban presentando resistencia frente a su política sindical a lo largo de su gobierno. Ambas temáticas han sido numerosamente abordadas por escritos apologéticos del franquismo y detractores del peronismo. Pero aparecen generalmente ausentes dentro de la historiografía profesionalizada en la actualidad, como factores de peso a la hora de una explicación global de la relación entre dichos fenómenos con los movimientos obreros de sus países. Algunos trabajos que van en ese sentido para el caso español, se reflejan en las propuestas de investigación de José Moreno Luzón, o los trabajos de Francisco Cobo Romero y Teresa Ortega López. Seguramente la investigación más centrada en este aspecto, es la reciente obra de Carme Molinero. ${ }^{12}$ En Argentina en cambio, son escasos los ejemplos a

\footnotetext{
${ }^{11}$ Este proceso es desarrollado, entre otros estudios, en la primera parte del libro de MOLINERO, Carme e YSÀS, Pere. Productores disciplinados y minorías subversivas: clase obrera y conflictividad laboral en la España franquista, Madrid: Siglo XXI, 1998.

12 MORENO LUZÓN, José Javier. "El estudio de los apoyos sociales del franquismo. Una propuesta metodológica", en CASTILLO, Santiago (coord.), La historia social en España, actualidad y perspectivas: Actas del I Congreso de la Asociación de Historia Social, Zaragoza, septiembre, 1990. Madrid: Siglo XXI, 1991. COBO
} 
remarcar, pero una pequeña aproximación es la que he realizado en torno a mis estudios del movimiento obrero en la provincia de Tucumán. ${ }^{13}$

Sin duda, como hemos mencionado, existen diferencias evidentes entre los regímenes. En primer lugar el franquismo se instauró tras una sangrienta contienda civil que sirvió además de antesala para una ofensiva fascista a nivel mundial, la cual se prolongó durante la II guerra mundial. Pero también son diferentes las consecuencias a largo plazo con respecto a la clase obrera. Mientras, tras la transición y el parcial desmantelamiento del franquismo, en España resurgieron las viejas corrientes ideológico-políticas de la preguerra (con las inevitables transformaciones provocadas por los años transcurridos y las transformaciones estructurales acaecidas en el mundo y en el propio país), en Argentina la gran mayoría de los trabajadores mantiene su identificación con el movimiento peronista, situación que desvela a los científicos sociales en su afán de explicar las razones de dicha continuidad. Además en el país europeo, durante la transición política hacia la democracia se legisló en favor de una pluralidad ideológico-política que permite la existencia de diversos sindicatos en cada rama de la producción, en tanto en el Estado latinoamericano se continúa hasta hoy con la ley de asociaciones profesionales dictada durante el peronismo (y reafirmada durante el tercer mandato de su líder a partir de 1973), la cual sólo permite un sindicato oficial en cada sector de la producción. Esto último conlleva, entre otras cosas, al hecho de que los historiadores, que naturalmente escriben desde su propio presente, sean testigos y protagonistas de dichas consecuencias disimiles y por ende entiendan ambos procesos como antagónicos.

No obstante, como hemos marcado en la introducción, no se trata de destacar las similitudes, sino por el contrario de analizar los contrastes en el marco, en este caso, de dos procesos que implicaron el uso de la fuerza estatal para disciplinar, jerarquizar y finalmente adosar al movimiento obrero a la estructura del Estado. En ese sentido la sugerencia que se propone desde este trabajo es que, al analizar los sucesos de dicha época respecto a los obreros y sus organizaciones en cada uno de sus países, los historiadores tengan como referencia y punto de comparación lo sucedido en los casos argentino y español, correspondientemente. Consideramos esto posible principalmente respecto a algunas preguntas puntuales, como ser: qué elementos del movimiento obrero estatizado pueden rastrearse en la etapa precedente, cuáles son las transformaciones puntuales en la organización y dinámica sindicales bajo el franquismo y el peronismo, cuáles son los grados de resistencia y aceptación de dichos procesos, cuál es el grado de independencia que ha podido mantener el gremialismo a lo largo de cada uno de estos gobiernos, etc.

ROMERO, Francisco y ORTEGA LÓPEZ, Teresa María. “No sólo Franco. La heterogeneidad de los a poyos sociales al régimen franquista y la composición de los poderes locales. Andalucía, 1936-1948", Historia social, № 51, Valencia, 2005, pp. 49-72. MOLINERO, Carme. La captación de las masas: política social y propaganda en el régimen franquista, Madrid: Cátedra, 2005.

${ }^{13}$ PILIPONSKY, Esteban. “Autonomía y estatización. Rupturas en el sindicalismo tucumano frente al fenómeno peronista", Historia Regional, Año XXIV, № 29, Rosario, 2011. En realidad la tendencia en la historiografía argentina, más que analizar los aspectos coercitivos del régimen, es a remarcar y ampliar la idea de consenso ya no sólo para los primeros años del gobierno, sino para la totalidad de su mandato. 
Además existe un momento particular de dichos regímenes en donde el cotejo puede ser de mayor riqueza, y esto es en los primeros años de la segunda posguerra. Tras la victoria aliada, el contexto occidental cambia desde la derrota bélica de los fascismos y de las ideologías corporativistas, hacia la exaltación de las democracias burguesas en detrimento de la corriente soviética. En los primeros años de la guerra fría, tanto el peronismo como el franquismo lograron asentar sus gobiernos a pesar de las presiones surgidas desde los EEUU, y se volvieron paladines de la lucha anti comunista. Allí es, seguramente, donde sus políticas sobre el movimiento obrero concentran las mayores analogías.

\section{CONSIDERACIONES FINALES}

Naturalmente existen causas que explican la escasa inclinación de los historiadores argentinos y españoles a tomar los casos y las investigaciones del otro país, como una referencia a la hora de los estudios propios de sus sociedades. Tanto España como Argentina se ubican en la periferia en cuanto a los ámbitos de producción científico-social a nivel mundial, situación que se vio agravada durante la segunda mitad del siglo XX por los diferentes sucesos políticos ocurridos en uno y otro país. Esto lleva a que las referencias respecto al exterior se hagan con mayor asiduidad hacia las metrópolis. La facilidad de ello no se reduce al cumulo de producción o al avance epistemológico en aquellas zonas, sino también a la mayor circulación de sus obras entre los países menos desarrollados.

Sin embargo para los casos aquí mencionados, existen condiciones que facilitan el diálogo entre ambas experiencias y vuelven llamativa la falencia de las mismas. En primer lugar, la comodidad que implica la inexistencia de barreras idiomáticas pues en los dos países se habla la misma lengua. $Y$, en segundo término, las similitudes tanto en la cultura política como en ciertos aspectos de su desarrollo económico.

Específicamente respecto a las temáticas del movimiento obrero, es innegable que el contexto de producción de la misma sufrió diversos obstáculos en los dos países. En las décadas siguientes a la segunda posguerra existió una sistemática censura de los diferentes gobiernos en relación a este objeto de estudio. Años después hubo una subestimación de dicha temática dentro de las ciencias sociales que lleva ya 30 años, en contraste al auge que habían tenido los escritos sobre clase obrera en los convulsionados años ' 60 y ' 70 . De todos modos actualmente, ambas dificultades parecen mayormente superadas y comienza a volverse necesario entonces comparar las realidades de uno y otro país en las investigaciones a futuro.

Finalmente, respecto al marco temporal que proponemos en el presente trabajo, existe una tendencia mayoritaria a no contrastar los procesos políticos que produjeron la estatización del movimiento obrero en cada uno de estos países, lo cual conlleva consecuencias a la hora de las comparaciones en la totalidad del período. Sin duda tiene un peso importante aquí la valoración que se les dio a dichos regímenes en cada caso. Por un lado el franquismo, claramente emparentado con los fascismos europeos de la época y 
producto de la excepcionalidad de su imposición mediante una guerra civil, ha sido analizado principalmente en su aspecto autoritario y dictatorial, sobre todo con respecto al movimiento obrero. Por el contrario, el peronismo se ha visto desde un tiempo a esta parte como una opción (en algunas interpretaciones como la única) para el desarrollo de las organizaciones obreras dentro del marco legal e institucional del Estado. Esta antinomia en las lecturas lleva a ver ambos fenómenos como incomparables. Por el contrario, la afinidad en los objetivos de uno y otro gobierno respecto a la política sindical que buscaron aplicar, y la similitud en los resultados en relación a la estatización institucional del movimiento obrero, al menos el "sindicalismo oficial" en el caso español, nos lleva a pensar que a pesar de las evidentes diferencias ambos procesos son claramente cotejables.

\section{REFERENCIAS BIBLIOGRÁFICAS ${ }^{14}$}

\section{ESPAÑA}

\section{DEBATES HISTORIOGRÁFICOS}

AAVV. Cuadernos de historia contemporánea. Dossier: Manuel Tuñón e Lara, diez años después. La huella de un legado, № 30, 2008, pp. 83-104. En línea: http://dialnet.unirioja.es/servlet/listaarticulos?tipo_busqueda=ANUALIDAD\&revis ta_busqueda $=1526 \&$ clave_busqueda $=2008$

BARRIO ALONSO, Ángeles. "Clase obrera y movimiento obrero: ¿dos compañeros inseparables?", Cuadernos de historia contemporánea, № 30, 2008, pp. 83-104. En línea: http://dialnet.unirioja.es/servlet/articulo?codigo=2816530

CEAMANOS LLORENS, Roberto. "De la ruptura a la convergencia. La historiografía social obrera española y francesa (1939-1982)", Historia social, № 61, Valencia, 2008, pp. 147-168.

CRUZ MARTÍNEZ, Rafael. "El órgano de la clase obrera. Los significados de movimiento obrero en la España del siglo XX", Historia social, № 53, Valencia, 2005, pp. 155174.

GABRIEL SIRVENT, Pere. "A vueltas y revueltas con la historia social obrera en España. Historia obrera, historia popular e historia contemporánea", Historia social, № 22, Valencia, 1995, pp. 43-53.

GABRIEL SIRVENT, Pere. "Una historia social y política del mundo del trabajo y los trabajadores", Vasconia: Cuadernos de historia - geografía, № 30, 2000, pp. 1531. En línea: http://www.euskomedia.org/PDFAnlt/vasconia/vas30/30015031.pdf

\footnotetext{
${ }^{14}$ He dividido la bibliografía por país y por tema. Aunque algunos textos no son específicamente acerca del movimiento obrero, están incluidos con la idea de que pueden engrosar el conocimiento sobre el mismo, y su ordenación en cada tópico está pensada en ese sentido. El objetivo de esta división es que la misma sea usada como guía por los investigadores que la consulten. Como toda clasificación, la misma es arbitraria y flexible, por lo cual puede haber textos híbridos entre una lista y otra.
} 
PANIAGUA, Javier. "Otra vuelta de tuerca las interpretaciones del arraigo del anarquismo en España. ¿Sigue la polémica?”, Germinal: revista de estudios libertarios, №. 1, 2006, pp. 5-22. En línea: http://dialnet.unirioja.es/servlet/articulo?codigo $=2044940$

PERE SIRVENT, Gabriel. "Mundo del trabajo y cultura política obrera en España (siglo XX)", en FERNÁNDEZ, Roberto y CASTILLO, Santiago (Coord.), Historia social y ciencias sociales / actas del IV Congreso de Historia Social de España, Lleida, 12-15 de diciembre de 2000, Leida: Milneio, 2001.

PÉREZ LEDESMA, Manuel y Álvarez Junco, José. "Historia del movimiento obrero ¿una segunda ruptura?", en IZQUIERDO MARTÍN, Jesús y SÁNCHEZ LEÓN, Pablo (Coord.) Clásicos de historia social de España: una selección crítica, Valencia: UNED, 2000, pp. 259-280.

PÉREZ LEDESMA, Manuel. "Historia del movimiento obrero. Viejas fuentes, nueva metodología", Studia historica. Historia contemporánea, № 6-7, 1988-1989, pp. 715.

\section{CORRIENTES POLÍTICAS}

ÁLVAREZ JUNCO, José. "La teoría política del anarquismo", en Vallespín Oña, Fernando (Coord.), Historia de la teoría política, Madrid: Alianza, 1995, pp. 262-305.

ANDREASSI CIERI, Alejandro. "Continuidad y ruptura: el sindicalismo revolucionario, 18951914", Profesor Nazario González: una historia abierta, Barcelona: Universidad Autónoma de Barcelona, 1998, pp. 411-420.

ANDREASSI CIERI, Alejandro. Libertad también se escribe en minúscula: anarcosindicalismo en Sant Adrià de Besòs (1925-1939), Barcelona: Hacer, 1996.

ARÓSTEGUI SÁNCHEZ, Julio. "EL sindicalismo socialista en los años treinta", Leviatán: Revista de hechos e ideas, № 53-54, 1993, Madrid, pp. 125-154.

BARRIO ALONSO, Ángeles. Anarquismo y anarcosindicalismo en Asturias, 1890-1936, Madrid: Siglo XXI, 1988.

CARO CANCELA, Diego. "Cien años de anarcosindicalismo", Andalucía en la historia, №. 31, 2011, pp. 60-67.

CASANOVA RUIZ, Julián. De la calle al frente. El anarcosindicalismo en España (1931-1939), Barcelona: Crítica, 1997.

COBO ROMERO, Francisco. Por la Reforma Agraria hacia la Revolución. El sindicalismo agrario socialista durante la II República y la Guerra Civil, 1930-1939, Granada: Universidad de Granada, 2007.

HERRERÍN LÓPEZ, Ángel. La CNT durante el franquismo : clandestinidad y exilio (1939-1975), Madrid: Siglo XXI, 2004.

MARÍN, Dolors. Anarquistas: un siglo de movimiento libertario en España, Barcelona: Ariel, 2010.

MATEOS LÓPEZ, Abdón. "Comunistas, Socialistas y Sindicalistas ante las Elecciones del Sindicato Vertical 1944-1967", Espacio, tiempo y forma, Serie V, Historia 
contemporánea, № 1, 1988, pp. 379-412. En línea:

http://e-spacio.uned.es/fez/eserv.php?pid=bibliuned:ETFSerie5-36EA243C-D54A-

D1C0-2472-3DC38298C40B\&dsID=PDF

NAVARRO COMAS, Rocío. "El Frente Único, las Alianzas Obreras y el Frente Popular. La evolución teórica de los anarquistas frente a la colaboración obrera", Melanges de la Casa de Velázquez, № 41, 1, 2011, Madrid, pp. 103-120.

VEGA, Eulàlia. "Anarquismo y sindicalismo durante la Dictadura y la República", Historia social, Valencia, № 1, 1988, pp. 55-62.

VEGA, Eulàlia. Anarquistas y sindicalistas durante la Segunda República. La CNT y los sindicatos de oposición en el País Valenciano, Valencia: Alfons el Magnànim, 1987.

\section{FORMAS DE ORGANIZACIÓN Y LUCHA}

ANDREASSI CIERI, Alejandro. "La conflictividad laboral en Cataluña a comienzos del siglo XX. Sus causas", Historia social, № 29, Valencia, 1997, pp. 21-43.

ARENAS POSADAS, Carlos. "En torno a la aristocracia obrera. El caso sevillano. 1898-1915", Estudios de historia social, №. 42-43, 1987, pp. 181-207.

CASTELLS ARTECHE, Luis. Los trabajadores en el País Vasco, 1876-1923, Madrid: Siglo XXI, 1993.

EALHAM, Chris. La lucha por Barcelona: clase, cultura y conflicto, 1898-1937, Madrid: Alianza, 2005.

FORCADELL ÁLVAREZ, Carlos. "De la huelga general al golpe militar. El protagonismo sindical en la crisis de 1917 a 1923", Historia 16, № 201, 1993, pp. 20-28.

GONZÁLEZ DE MOLINA NAVARRO, Manuel Luis y CARO Cancela, Diego (coord.), "La utopía racional: estudios sobre el movimiento obrero andaluz", Granada: Universidad de Granada, 2001.

MACARRO VERA, José Manuel. "Sindicalismo y política”, Ayer, № 20, Madrid, 1995, pp. 141172.

MARTÍN RAMOS, José Luis. De la tregua a la expansión reivindicativa: El arranque de la explosión huelguística en Barcelona (1914-1916)", Historia social, № 5, Valencia, 1989, pp. 115-128.

MATEOS LÓPEZ, Abdón. "Sindicalismo socialista y movimiento obrero durante la dictadura franquista (1939-1976)", en JULIÁ DÍAZ, Santos (Coord.), El socialismo en España: desde la fundación del PSOE hasta 1975, Madrid: Editorial Pablo Iglesias, 1986, pp. 317-348.

MORALES MUÑOZ, Manuel. "Un espacio propio. Sociabilidad e identidad obrera en Andalucía", Historia social, № 56, Valencia, 2006, pp. 53-70.

ORTEGA LÓPEZ, María Teresa. Trabajadores y jornaleros contra patronos y verticalistas: conflictividad laboral y reivindicación democrática en una provincia periférica y escasamente desarrollada: Granada, 1936-1982, Granada: Universidad de Granada, 2001. 
PANIAGUA FUENTES, Francisco Javier. "Trayectoria del sindicalismo español”, Historia 16, № 181, 1991, pp. 107-120.

SÁNCHEZ PÉREZ, Francisco. "Las protestas del trabajo en la primavera de 1936", Melanges de la Casa de Velázquez, № 41, 1, 2011, Madrid, pp. 77-101.

SEVILLANO CALERO, Francisco. "Consenso y violencia en el "nuevo estado" franquista. Historia de las actitudes cotidianas", Historia social, № 46, Valencia, 2003, pp. 159-172.

RELACIÓN CON EL ESTADO, GOBIERNO Y PARTIDOS

APARICIO, Miguel A. El sindicalismo vertical y la formación del estado franquista, Barcelona: Eunibar, 1980.

ARÓSTEGUI SÁNCHEZ, Julio (coord.). "La república de los trabajadores. La Segunda República y el mundo del trabajo", Madrid: Fundación Francisco Largo Caballero, 2006.

ARÓSTEGUI SÁNCHEZ, Julio. "Indalecio Prieto y Largo Caballero. Divergencias y convergencias en el socialismo español (1923-1946)", en Mateos López, Abdón (coord.), Indalecio Prieto y la política española, Madrid: Fundación Pablo Iglesias, 2008, pp. 123-162.

BERNAL GARCÍA, Francisco Javier. El sindicalismo vertical: burocracia, control laboral y representación de intereses en la España franquista, 1936-1951, Madrid: Centro de Estudios Políticos y Constitucionales, 2010.

BORDERÍAS MONDEJAR, Cristina (ed. lit.). Género y políticas del trabajo en la España contemporánea, 1836-1936, Barcelona: Icaria, 2007.

COBO ROMERO, Francisco y ORTEGA LÓPEZ, María Teresa. "No sólo Franco. La heterogeneidad de los a poyos sociales al régimen franquista y la composición de los poderes locales. Andalucía, 1936-1948”, Historia social, № 51, Valencia, 2005, pp. 49-72.

COBO ROMERO, Francisco y ORTEGA LÓPEZ, María Teresa. Franquismo y posguerra en Andalucía oriental. Represión, castigo a los vencidos y apoyos sociales al régimen franquista, 1936-1950, Granada: Universidad de Granada, 2005.

JULIÁ DÍAZ, Santos (Coord.), El socialismo en España: desde la fundación del PSOE hasta 1975, Madrid: Editorial Pablo Iglesias, 1986.

LANERO TÁBOAS, Daniel. "Sobre el ecuadramiento de los campesinos y la agricultura en el tiempo de los fascismos. Una comparación entre nazismo y franquismo", Ayer, o 83, 2011, pp. 53-76.

MARTíNEZ FIOL, David. "La revolución de los funcionarios y el mito del antiestatismo libertario en la lucha por los empleos públicos de Cataluña (1931-1939)", Congreso La Guerra Civil Española 1936 - 1939, 2006. En línea:

http://www.secc.es/media/docs/4_2_Martinez_Fiol.pdf

MOLINERO, Carme e YSÀS, Pere. Productores disciplinados y minorías subversivas: clase obrera y conflictividad laboral en la España franquista, Madrid: Siglo XXI, 1998. 
MOLINERO, Carme. La captación de las masas: política social y propaganda en el régimen franquista, Madrid: Cátedra, 2005.

MORENO LUZÓN, José Javier. "El estudio de los apoyos sociales del franquismo. Una propuesta metodológica", en CASTILLO, Santiago (Coord.), La historia social en España, actualidad y perspectivas: Actas del I Congreso de la Asociación de Historia Social, Zaragoza, septiembre, 1990, Madrid: Siglo XXI, 1991.

PÉREZ LEDESMA, Manuel. "Partido y sindicato. Unas relaciones no siempre fáciles", en JULIÁ DÍAZ, Santos (Coord.), El socialismo en España: desde la fundación del PSOE hasta 1975, Madrid: Editorial Pablo Iglesias, 1986, pp. 213-229.

\section{OTRAS OBRAS IQUE EXCEDEN O NO ESTÁN INCLUIDAS EN LA CATEGORIZACIÓN PROPUESTA)}

CASTILLO, Santiago (coord.), El trabajo a través de la historia: actas del IIo congreso de la Asociación de Historia Social, abril de 1995, Córdoba, 1996.

CASTILLO, Santiago (dir.). Historia de la UGT, 6 Tomos, Madrid: Siglo XXI, 2008-2011.

DUARTE MONTSERRAT, Ángel. "Republicanos, emigrados y patriotas. Exilio y patriotismo español en la Argentina en el tránsito del siglo XIX al XX", Ayer, № 47, 2002, pp. 57-80.

OYÓN, José Luis. "La ruptura de la ciudad obrera y popular. Espacio urbano, inmigración y anarquismo en la Barcelona de entreguerras, 1914-1936", Historia social, № 58, Valencia, 2007, pp. 123-150.

SÁNCHEZ JIMÉNEZ, José y VALVERDE, José María. Las claves del movimiento obrero, 18301930, Barcelona: Planeta, 1992.

\section{ARGENTINA}

\section{DEBATES HISTORIOGRÁFICOS}

AAVV. Nuevo Topo. Revista de historia y pensamiento crítico. Dossier: La Burocracia Sindical, № 7, Buenos Aires, 2010.

CAMARERO, Hernán. "Consideraciones sobre la historia social de la Argentina urbana en las décadas de 1920 y 1930: clase obrera y sectores populares", Nuevo Topo. Revista de historia y pensamiento crítico, № 4, septiembre-octubre 2007, Buenos Aires, pp. 35-60.

IÑIGO CARRERA, Nicolás. "La clase obrera argentina a comienzos de los '30. Sistema institucional, partidos y clase: apuntes para una lectura crítica", jornadas: a 40 años del Cordobazo: ciento treinta años de historia de luchas de la clase obrera en Argentina, 1878-2008, 2009.

En línea: http://historiapolitica.com/datos/biblioteca/icarrera1.pdf 
KINDGARD, Adriana. "Mundo popular y cambio social en el Jujuy de los años '30. Nuevas fuentes y nuevos rostros del sujeto político", Escuela de Historia, revista digital № 1, anuario no 22, Rosario, 2009-2010. En línea: http://web.rosarioconicet.gov.ar/ojs/index.php/Anuario/article/viewFile/51/75

NIETO, Agustín. "Notas críticas en torno al sentido común historiográfico sobre 'el anarquismo argentino'", A contra corriente, una revista de historia social y literatura de América Latina, Vol. 7, № 3, 2010, pp. 219-248. En línea: http://www.ncsu.edu/acontracorriente/spring_10/articles/Nieto.pdf

SURIANO, Juan. "Una aproximación a la definición de la cuestión social en Argentina", en Suriano, Juan (comp.), La cuestión social en Argentina 1870-1943, Buenos Aires: La Colmena, 2000.

ZIMMERMANN, Eduardo. "Los intelectuales, las ciencias sociales y el reformismo liberal: Argentina 1890-1916", Desarrollo económico, no 124. v31, 1992, pp. 545-564.

\section{CORRIENTES POLÍTICAS}

ANAPIOS, Luciana. "Una promesa de folletos. El rol de la prensa en el movimiento anarquista en la Argentina (1890-1930)", A contra corriente, una revista de historia social y literatura de América Latina, Vol. 8, № 2, 2011, pp. 1-33. En línea: http://www.ncsu.edu/acontracorriente/winter_11/articles/Anapios.pdf

ASCOLANI, Adrián, "Corrientes sindicales agrarias en la Argentina. Socialismo, anarco comunismo y sindicalismo (1900-1922)", Anuario, segunda época № 15. Escuela de Historia, Facultad de Humanidades y Artes, UNR, 1991-1992.

BELKIN, Alejandro. Sobre los orígenes del sindicalismo revolucionario en Argentina, Cuadernos de Trabajo № 74, Buenos Aires: Ediciones del Centro Cultural de la Cooperación Floreal Gorini, 2006.

BILSKY, Edgardo J. La FORA y el movimiento obrero (1900-1910), vols. 1 y 2, Buenos Aires: CEAL, 1985.

CAMARERO, Hernán. A la conquista de la clase obrera. Los comunistas y el mundo del trabajo en la Argentina, 1920-1935, Buenos Aires: Siglo XXI, 2007.

LOBATO, Mirta Zaida. "El peligro rojo: comunismo y anticomunismo en la experiencia obrera de los trabajadores de la carne, 1930-43", en MASÉS, Enrique: Historia Social 1990-2000, General Roca (Río Negro): PubliFadecs, Universidad Nacional del Comahue, 2000, pp. 151-182.

LÓPEZ TRUJILLO, Fernando. Vidas en rojo y negro. Una historia del anarquismo en la "Década Infame", La Plata: Letra Libre, 2005.

MARTíNEZ MAZZOLA, Ricardo H. "Campeones del proletariado. El periódico El Obrero y los comienzos del socialismo en la Argentina", Políticas de la memoria, 4, verano 2003/2004, pp. 91-110.

MATSUSHITA, Hiroshi. Movimiento obrero argentino, Buenos Aires: Hypamérica, 1986. 
OVED, laacov. El anarquismo y el movimiento obrero en Argentina, México: Siglo XXI Editores, 1978.

PASCUCCI, Silvina. Costureras, monjas y anarquistas: trabajo femenino, Iglesia y lucha de clases en la industria del vestido, Buenos Aires, 1890-1940, Buenos Aires: Ediciones RyR, 2007.

RUOCCO, Laura. "Mujeres obreras y sindicalismo anarquista. Dos paradigmas historiográficos (Mar del Plata 1942)", Revista de Historia Bonaerense, Morón (Buenos Aires), 2009.

SURIANO, Juan. Anarquistas. Cultura y política libertaria en Buenos Aires, 1890-1910, Buenos Aires: Manantial, 2001.

\section{FORMAS DE ORGANIZACIÓN Y LUCHA}

ACHA, Omar. Las huelgas bancarias, de Perón a Frondizi (1945-1962): contribución a la historia de las clases sociales en la Argentina, Buenos Aires: Ediciones del CCC, 2008.

ANDREASSI Cieri, Alejandro. Movimiento huelguístico y socialismo en Argentina. Buenos Aires, 1895-1910, Barcelona: UAB, $1995 .^{15}$

BASUALDO, Victoria. "Los delegados y las comisiones internas en la historia argentina. Una mirada de largo plazo, desde sus orígenes hasta la actualidad", Instituto de Estudios y Capacitación de la Federación Nacional de Docentes Universitarios CONADU, Suarez, 2010, pp. 256-316. En línea: http://www.iec-conadu.org.ar/images/Libro\%20ECONOMIA\%20FINAL.pdf

CARUSO, Laura. "La huelga general marítima del Puerto de Buenos Aires, diciembre 1916", Revista de Estudios Marítimos y Sociales, Año 1, № 1, Mar del Plata, 2008.

CERUSO, Diego. Comisiones internas de fábrica. Desde la huelga de la construcción de 1935 hasta el golpe de Estado de1943, Buenos Aires: PIMSA, 2010.

CONTRERAS, Gustavo Nicolás. "Clase obrera y peronismo. La "gran" huelga marítima de 1950", XXI Jornadas de historia económica, Asociación Argentina de Historia Económica, Caseros (Buenos Aires), 2008. En línea:

http://historiapolitica.com/datos/biblioteca/contreras2.pdf

D'ANTONIO, Débora C. La lucha de las mujeres en la gran huelga de la construcción (19351936), Buenos Aires: Desde el Subte, 2009.

FALCÓN, Ricardo. Los orígenes del movimiento obrero (1857-1899), Buenos Aires: CEAL, 1984.

GARZÓN ROGÉ, Mariana. "La experiencia sindical de los trabajadores vitivinícolas durante el peronismo", XXI Jornadas de historia económica, Asociación Argentina de Historia Económica, Caseros (Buenos Aires), 2008. En línea: http://xxijhe.fahce.unlp.edu.ar/programa/descargables/GarzonRoge.pdf

\footnotetext{
${ }^{15}$ El Dr. Andreassi es un investigador argentino radicado en España. Sus investigaciones acerca de su país de origen son muy poco conocidas en el ámbito académico del mismo.
} 
GURBANOV, Andrés y RODRÍGUEZ, Sebastián. "La huelga metalúrgica de 1942 y la crisis de la dirigencia comunista en los orígenes del comunismo", Nuevo Topo, № 4, Buenos Aires, 2007.

IÑIGO CARRERA, Nicolás. La estrategia de la clase obrera, 1936, Buenos Aires: La Rosa Blindada-PIMSA, 20001-293.

IZQUIERDO, Roberto. Tiempo de trabajadores: los obreros del tabaco, Buenos Aires: Imago Mundi, 2008.

KORZENIEWICZ, Roberto P. "Las vísperas del peronismo. Los conflictos laborales entre 1930 y 1943, Desarrollo Económico. Revista de Ciencias Sociales, XXXIII, 131, octubrediciembre 1993, pp. 323-354.

POY, Lucas. "La "huelga grande" de 1896 en los orígenes del movimiento obrero de Buenos Aires", A contra corriente, una revista de historia social y literatura de América Latina, Vol. 9, № 1, 2011, pp. 144-154. En línea:

http://acontracorriente.chass.ncsu.edu/index.php/acontracorriente/article/view/ 104/68

RODRÍGUEZ, Florencia y RUBINSTEIN, Gustavo. "EI mundo del trabajo en la industria azucarera tucumana durante los años '30", Primer congreso de estudios sobre el peronismo: la primera década, Mar del Plata, 2008. En línea:

http://redesperonismo.com.ar/archivos/CD1/PP/gutierrez.pdf

SCHIAVI, Marcos. La resistencia antes de la resistencia. La huelga metalúrgica y las luchas obreras de 1954, Buenos Aires: El Colectivo, 2008.

VIDELA, Oscar: "Desarrollo agroexportador y conflictividad social. 1912-1930", en VIDELA, Oscar (dir. del tomo) Nueva Historia de Santa Fe. El siglo veinte. Problemas sociales, políticas de Estado y economías regionales (1912-1976), Rosario: Prohistoria y La Capital, 2006.

\section{RELACIÓN CON EL ESTADO, GOBIERNO Y PARTIDOS}

ADELMAN, Jeremy. "El Partido Socialista argentino", en. LOBATO, Mirta (dir.): El progreso, la modernización y sus límites (1880-1916), t. V de la Nueva Historia Argentina, Buenos Aires: Sudamericana, 2000, pp. 261-290.

CAMARero, Hernán. y HerRerA, Carlos M. (eds.). El Partido Socialista en Argentina. Sociedad, política e ideas a través de un siglo, Buenos Aires: Prometeo Libros, 2005.

CORREA, Rubén Emilio y ABRAHAN, Carlos Fernando. "Nota para una historia de los partidos políticos en Salta. Radicalismo y organización obrera. La experiencia del Centro Obrero Radical (C.O.R), 1926-1929", Documento de Trabajo № 10, Córdoba, 2006. En línea: http://historiapolitica.com/datos/biblioteca/cean10.pdf

DEL CAMPO, Hugo. Sindicalismo y peronismo. Los comienzos de un vínculo perdurable, Buenos Aires: CLACSO, 1983.

DI TELLA, Torcuato S. Perón y los sindicatos. El inicio de una relación conflictiva, Buenos Aires: Ariel, 2003. 
DOYON, Louise M. Perón y los trabajadores. Los orígenes del sindicalismo peronista, 19431955, Buenos Aires: Siglo XXI Editora Iberoamericana, 2006.

FALCÓN, Ricardo. "Izquierdas, régimen político, cuestión étnica y cuestión social en Argentina (1890-1912)", Anuario Escuela de Historia, Facultad de Humanidades y Artes, UNR, segunda época, 12, Rosario, 1986-1987.

HOROWITZ, Joel. Los sindicatos, el Estado y el surgimiento de Perón, 1930-1946, Buenos Aires: Eduntref, 2004.

PAVETTI, Oscar. "Sindicalismo azucarero y peronismo (1949)", en BONANO, Luís (Coord.). Estudios de historia social de Tucumán. Volumen I, Tucumán: Facultad de Filosofía y Letras, 1999.

PILIPONSKY, Esteban. "Autonomía y estatización. Rupturas en el sindicalismo tucumano frente al fenómeno peronista", Historia Regional, Año XXIV, № 29, Rosario, 2011.

RUBINSTEIN, Gustavo. Los sindicatos azucareros en los orígenes del peronismo, Tucumán: Facultad de Ciencias Económicas UNT, 2005.

SARTELLI, Eduardo. "Celeste, Blanco y Rojo. Democracia, nacionalismo y clase obrera en la crisis hegemónica (1912-1922)", Razón y Revolución, № 2, Buenos Aires, primavera de 1996, pp.48-78.

TORRE, Juan Carlos. La vieja guardia sindical y Perón. Sobre los orígenes del peronismo, Buenos Aires: Sudamericana, 1990.

TORTTI, María Cristina "Estrategia del Partido Socialista. Reformismo político y reformismo sindical", Conflictos y Procesos de la Historia Argentina Contemporánea, no 34, Buenos Aires: CEAL, 1989.

ULIVARRI, María. "Movimiento obrero, Estado y política en Tucumán en la segunda mitad de la década del treinta", XXI Jornadas de historia económica, Asociación Argentina de Historia Económica, Caseros (Buenos Aires), 2008. En línea: http://xxijhe.fahce.unlp.edu.ar/programa/descargables/Ullivarri.pdf

VIDELA, Oscar; PASQUALI, Laura y DIZ, Diego. "Política, sindicatos e izquierdas en contextos locales en el sudeste santafesino durante los años treinta", III Jornadas de Ciencia y Tecnología, Rosario: Universidad Nacional de Rosario Editora, 2009.

\section{OTRAS OBRAS IQUE EXCEDEN O NO ESTÁN INCLUIDAS EN LA CATEGORIZACIÓN PROPUESTA)}

GODIO, Julio; El movimiento obrero argentino (1930-43). Socialismo, comunismo y nacionalismo obrero; Buenos Aires: Legasa, 1989.

KABAT, Marina. "Fatto in casa. El trabajo a domicilio en la industria argentina del calzado y sus vínculos con el desarrollo fabril, 1870 - 1940”, Razón y Revolución, №9, 2002.

SANTA CRUZ, Claudia. "iEl colectivo es del pueblo! El movimiento de resistencia antimonopólica de los usuarios contra la expropiación de los autos colectivos en 1942", XXI Jornadas de historia económica, Asociación Argentina de Historia 
Económica, Caseros (Buenos Aires), 2008. En línea: http://xxijhe.fahce.unlp.edu.ar/programa/descargables/SantaCruz.pdf

TARCUS, Horacio. Marx en la Argentina. Sus primeros lectores obreros, intelectuales y científicos, Buenos Aires: Siglo veintiuno editores, 2007. 